\title{
The Effect of Subsequent Stress-Induced Martensite Aging on the Viscoelastic Properties of Aged NiTiHf Polycrystals
}

\author{
Anton I. Tagiltsev ${ }^{1, * \mathbb{C}}$, Elena Y. Panchenko ${ }^{1}{ }^{\mathbb{D}}$, Ekaterina E. Timofeeva $^{1}$, Yuriy I. Chumlyakov ${ }^{1}$, \\ Ekaterina S. Marchenko ${ }^{1}$ and Ibrahim Karaman ${ }^{2}$ \\ 1 Laboratory for Physics of High-Strength Crystals, Siberian Physical-Technical Institute, Tomsk State \\ University, Lenina Str. 36, 634050 Tomsk, Russia; panchenko@mail.tsu.ru (E.Y.P.); katie@mail.tsu.ru (E.E.T.); \\ chum@phys.tsu.ru (Y.I.C.); mes@mail.tsu.ru (E.S.M.) \\ 2 Department of Materials Science \& Engineering, Texas A\&M University, College Station, TX 77843, USA; \\ ikaraman@tamu.edu \\ * Correspondence: antontgl@mail.tsu.ru
}

check for updates

Citation: Tagiltsev, A.I.; Panchenko, E.Y.; Timofeeva, E.E.; Chumlyakov, Y.I.; Marchenko, E.S.; Karaman, I. The Effect of Subsequent Stress-Induced Martensite Aging on the Viscoelastic Properties of Aged NiTiHf Polycrystals. Metals 2021, 11, 1890. https://doi.org/10.3390/ met11121890

Academic Editor: Daixiu Wei

Received: 13 October 2021

Accepted: 19 November 2021

Published: 23 November 2021

Publisher's Note: MDPI stays neutral with regard to jurisdictional claims in published maps and institutional affiliations.

Copyright: (c) 2021 by the authors. Licensee MDPI, Basel, Switzerland. This article is an open access article distributed under the terms and conditions of the Creative Commons Attribution (CC BY) license (https:/ / creativecommons.org/licenses/by/ $4.0 /)$.

\begin{abstract}
This study investigated the effect of stress-induced martensite aging under tensile and compressive stresses on the functional and viscoelastic properties in $\mathrm{Ni}_{50.3} \mathrm{Ti}_{32.2} \mathrm{Hf}_{17.5}$ polycrystals containing dispersed $\mathrm{H}$-phase particles up to $70 \mathrm{~nm}$ in size obtained by preliminary austenite aging at $873 \mathrm{~K}$ for $3 \mathrm{~h}$. It was found that stress-induced martensite aging at $428 \mathrm{~K}$ for $12 \mathrm{~h}$ results in the appearance of a two-way shape memory effect of $-0.5 \%$ in compression and $+1.8 \%$ in tension. Moreover, a significant change in viscoelastic properties can be observed: an increase in internal friction (by 25\%) and a change in elastic modulus in tensile samples. The increase in internal friction during martensitic transformation after stress-induced martensite aging is associated with the oriented growth of thermal-induced martensite. After stress-induced martensite aging, the elastic modulus of martensite $\left(E_{M}\right)$ increased by $8 \mathrm{GPa}$, and the elastic modulus of austenite $\left(E_{A}\right)$ decreased by $8 \mathrm{GPa}$. It was shown that stress-induced martensite aging strongly affects the functional and viscoelastic properties of material and can be used to control them.
\end{abstract}

Keywords: martensitic transformation; NiTiHf; stress-induced martensite aging; two-way shape memory effect

\section{Introduction}

NiTi-based shape memory alloys (SMAs) have attracted much scientific attention in recent decades. One of the most promising that possesses good functional properties at high temperatures is NiTiHf. Today, NiTiHf alloy is known as a promising material because of its high cyclic stability, corrosion resistance, strength properties, and the possibility to control transformation temperatures (TTs) and functional properties through precipitation. All these advantages make a NiTiHf system an almost ideal candidate for use in aerospace, automotive, robotic, and other industries.

Recently, another method was found to enhance the functional properties of hightemperature SMAs: stress-induced martensite aging (SIM-aging). It significantly affects the functional and mechanical properties of materials [1-4] due to the chemical stabilization (atomic reordering in accordance with martensite symmetry during martensite aging) and/or mechanical stabilization (pinning of interphase/twin boundaries by dislocations and point defects) of martensite [4]. The usage of SIM-aging can affect existing properties (such as increasing strength and transformation temperatures) or create new ones (such as producing a two-way shape memory effect (TWSME) or inducing rubber-like behavior). SIM-aging is known to be the most effective for high-temperature materials, where the ratio of the martensite starting temperature $\left(M_{S}\right)$ to the material's melting point is more than 0.2 [1]. 
However, there are still not enough studies about the effect of SIM-aging on the functional properties of different alloys, and there are no studies about the effect of SIMaging on viscoelastic properties. Thus, the aim of this work is to investigate the effect of SIM-aging on viscoelastic properties during B2-B19' martensitic transformations (MTs) in aged $\mathrm{Ni}_{50.3} \mathrm{Ti}_{32.2} \mathrm{Hf}_{17.5}$ polycrystals.

\section{Materials and Methods}

The $\mathrm{Ni}_{50.3} \mathrm{Ti}_{32.2} \mathrm{Hf}_{17.5}$ (at.\%) polycrystals were prepared by electroarc melting from high-purity $(99.99 \%)$ components (the melting point of studied NiTiHf system is around $1873 \mathrm{~K})$. The tensile samples of dog-bone shape with dimensions $12.5 \times 1.5 \times 2.5 \mathrm{~mm}$ and compressive samples of parallelepiped shape with dimensions $6 \times 3 \times 3 \mathrm{~mm}$ were cut using an electrodischarge machine (ARTA 123, Delta-test, Moscow, Russia). The specimens were mechanically ground and then polished in electrolyte to remove the hardened layer and prepare the specimens for mechanical experiments.

The NiTiHf polycrystals were studied after different heat treatments and were marked as follows: (1) polycrystals aged at $873 \mathrm{~K}$ for $3 \mathrm{~h}$ with subsequent cooling in air (type (I) samples) and (2) aged polycrystals (type (I) samples) subjected to additional thermomechanical treatment (SIM-aging), consisting of aging in a martensitic state at $428 \mathrm{~K}$ under constant stress (300 MPa for tensile samples and $400 \mathrm{MPa}$ for compressive samples) for $12 \mathrm{~h}$ (type (ISIM) samples). Austenite aging was chosen according to [5] in order to precipitate dispersed H-phase particles of a certain size. These particles do not undergo martensitic transformations but deform elastically, strengthen the materials, and increase transformation temperatures. The following SIM-aging was carried out using a dilatometer (IMRS-1, Microsplav, Tomsk, Russia), after which DMA (dynamical mechanical analysis) was carried out, with the same regime as in previous work [6]. First, the sample was heated to a temperature of $\mathrm{T}=533 \mathrm{~K}>A_{f}$ (austenite finish temperature). Then, a constant stress of $300 \mathrm{MPa}$ and $400 \mathrm{MPa}$ in tension and compression, respectively, was applied, and the sample was cooled down to a temperature of $\mathrm{T}=323 \mathrm{~K}<M_{f}$ (martensite finish temperature) to induce the direct B2-B19' MT. The next step was heating the sample up to a temperature of $\mathrm{T}=433 \mathrm{~K}<A_{S}$ (austenite start temperature) and maintaining this temperature for $12 \mathrm{~h}$. Finally, the sample was heated up to a temperature of $\mathrm{T}=533 \mathrm{~K}>A_{f}$ to induce the reverse B19'-B2 MT, and the applied stress was removed.

Differential scanning calorimetry (DSC) was performed for both types of samples using DSC 404F1 Pegasus (NETZSCH, Selb, Germany) with a cooling/heating rate of 10 $\mathrm{K} / \mathrm{min}$.

DMA was performed using DMA/SDTA 861 ${ }^{\mathrm{e}}$ (Mettler Toledo, Columbus, OH, USA) in tension upon cooling/heating at various frequencies from $0.1 \mathrm{~Hz}$ to $10 \mathrm{~Hz}$. The samples for DMA were obtained from the tensile species by cutting off the protruding parts.

The microstructures were examined via transmission electron microscopy (TEM) using equipment from the Nanotech Center of the Institute of Strength Physics and Materials Science, Siberian Branch of the Russian Academy of Sciences (JEM-2100, JEOL Ltd., Tokyo, Japan).

\section{Results}

The $\mathrm{Ni}_{50.3} \mathrm{Ti}_{32.2} \mathrm{Hf}_{17.5}$ polycrystals were studied after aging at $873 \mathrm{~K}$ for $3 \mathrm{~h}$ (type (I) samples) in order to precipitate the dispersed H-phase particles of a certain size, in line with [5,7]. Precipitates in polycrystals were distributed all over the sample volume regardless of grain boundaries, as shown in previous works [8]. The average grain size of the polycrystals was $\sim 36 \mu \mathrm{m}$ after aging. As shown in Figure 1, the precipitated $\mathrm{H}-$ phase particles had sizes of up to $70 \mathrm{~nm}$ (marked by arrows). These particles are oblate spindle-shaped (the ratio of their length to width is 3:3.5) and merge with each other to form a new system of elongated particles. As reported by [9], large particles with a spindle shape are elongated along the $\langle 011\rangle_{\mathrm{B} 2}$ direction and have typical reflexes of $\left.1 / 2<111\right\rangle_{\mathrm{B} 2}$. These H-phase particles possess face-centered orthorhombic lattice with parameters $\mathrm{a}=4 \mathrm{a}_{0}$, 
$\mathrm{b}=2 \sqrt{ } 2 \mathrm{a}_{0}$, and $\mathrm{c}=6 \sqrt{ } 2 \mathrm{a}_{0}[9,10]$. It should also be noted that the B19'-martensite variants possessed a high density of (001) compound nanotwins (marked by areas) and H-phase precipitates, which were completely embedded (Figure 1).

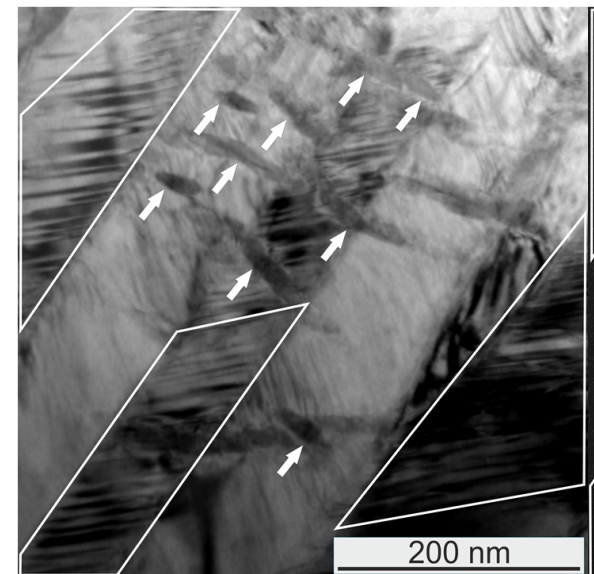

(a)

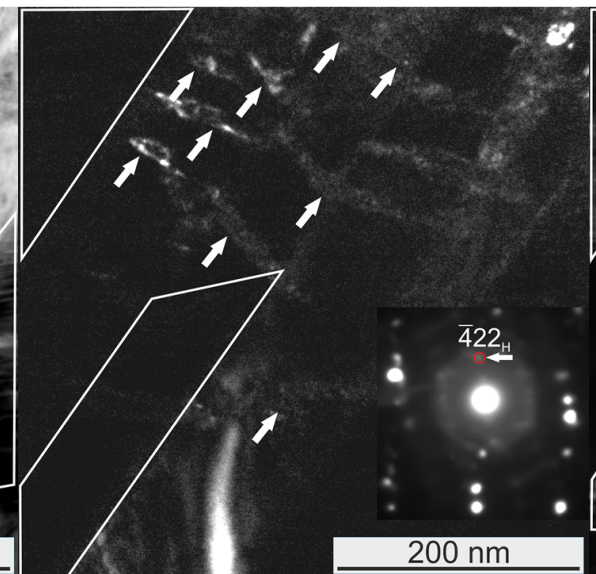

(b)

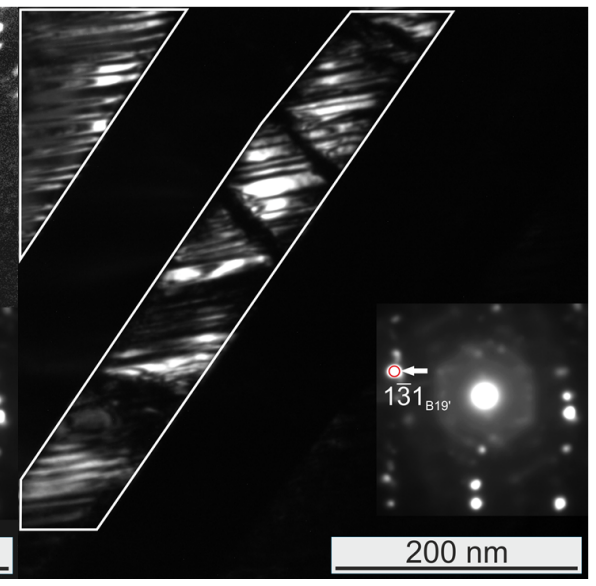

(c)

Figure 1. Bright field (a) and corresponding dark field (b,c) of internally twinned martensite (marked by areas) and H-phase particles (marked by arrows) in $\mathrm{Ni}_{50.3} \mathrm{Ti}_{32.2} \mathrm{Hf}_{17.5}$ polycrystals aged at $873 \mathrm{~K}$ for $3 \mathrm{~h}$ (type (I) samples).

The $\mathrm{Ni}_{50.3} \mathrm{Ti}_{32.2} \mathrm{Hf}_{17.5}$ polycrystals aged at $873 \mathrm{~K}$ for $3 \mathrm{~h}$ (type (I) samples) underwent B2-B19' MT at high temperatures of T > $373 \mathrm{~K}$. Figure 2 shows the dependence of the elastic modulus and tan $(\delta)$ (the characterization of internal friction) on the temperature in the studied type (I) and ( $\mathrm{I}_{\mathrm{SIM}}$ ) samples upon cooling/heating at different frequencies. It was experimentally shown that, in the initial polycrystals (type (I) samples), the elastic moduli of both phases are high (44-46 GPa and 38-40 GPa for martensite at a temperature of $273 \mathrm{~K}$ and austenite at a temperature of $523 \mathrm{~K}$, respectively). Moreover, a softening of the elastic modulus can be observed-its decrease as the starting temperature of MT approaches. Such behavior is one of the main features of thermoelastic MTs, characterized by the reconstruction of a crystal lattice that becomes soft, amenable, and easy to deform in order to create another phase due to the diffusionless process of atom displacement. The other feature of MT observed is a temperature peak of internal friction $\left(M_{p}\right.$ and $A_{p}$ in Table 1), which does not shift with a change in frequency (Figure 2). The SIM-aging resulted in a change in elastic modulus ( $E_{M}$ increased by $8 \mathrm{GPa}$ and $E_{A}$ decreased by $8 \mathrm{GPa}$ ) and an increase in internal friction (by $25 \%$ ) in the type ( $\mathrm{I}_{\mathrm{SIM}}$ ) samples compared with the type (I) samples. The peak temperatures of heat emission $\left(M_{p}\right)$ and heat absorption $\left(A_{p}\right)$ obtained during the DSC studies are in accordance with the peak temperatures of internal friction obtained during the DMA studies and characterize the forward and reverse B2-B19' MT (Table 1, Figure 2).

Table 1. The characteristics of martensite and austenite phases and $\mathrm{MT}$ in $\mathrm{Ni}_{50.3} \mathrm{Ti}_{32.2} \mathrm{Hf}_{17.5}$ polycrystals before and after SIM-aging.

\begin{tabular}{|c|c|c|c|c|c|c|c|c|}
\hline Heat Treatment & $\begin{array}{c}M_{p}(\mathrm{~K}) \\
( \pm 3)\end{array}$ & $\begin{array}{c}A_{p}(\mathrm{~K}) \\
( \pm 3)\end{array}$ & $\begin{array}{c}E_{M} \\
(\mathrm{GPa})\end{array}$ & $\begin{array}{c}E_{A} \\
(\mathrm{GPa})\end{array}$ & $\tan (\delta)$ & $\begin{array}{l}\varepsilon_{S M E}(\%) \\
( \pm 0.3)\end{array}$ & $\begin{array}{l}\varepsilon_{T W S M E}(\%) \\
( \pm 0.3)\end{array}$ & $\begin{array}{c}\Delta T_{T W S M E} \\
(\mathbf{K})( \pm 3)\end{array}$ \\
\hline $\begin{array}{l}\text { Aged at } 873 \mathrm{~K} \text { for } 3 \mathrm{~h} \\
\text { (type (I) samples) }\end{array}$ & 423 & 463 & 46 & 40 & $0.24 / 0.28$ & $\begin{array}{l}-1.0(\mathrm{c}) \\
+3.1(\mathrm{t})\end{array}$ & - & - \\
\hline $\begin{array}{c}\text { Aged at } 873 \mathrm{~K} \text { for } 3 \mathrm{~h} \text { with SIM-aging } \\
\text { (type (ISIM) samples) }\end{array}$ & 423 & 461 & 54 & 32 & $0.3 / 0.35$ & $\begin{array}{c}-0.8(\mathrm{c}) \\
-\end{array}$ & $\begin{array}{l}-0.5(\mathrm{c}) \\
+1.8(\mathrm{t})\end{array}$ & $\begin{array}{l}43(\mathrm{c}) \\
35(\mathrm{t})\end{array}$ \\
\hline $\begin{array}{l}\text { Aged at } 773 \mathrm{~K} \text { for } 3 \mathrm{~h} \mathrm{[6]} \\
\quad \text { (type (II) samples) }\end{array}$ & 416 & 453 & 38 & 33 & $0.16 / 0.22$ & $\begin{array}{l}-1.3(\mathrm{c}) \\
+5.3(\mathrm{t})\end{array}$ & - & - \\
\hline $\begin{array}{l}\text { Aged at } 773 \mathrm{~K} \text { for } 3 \mathrm{~h} \text { with SIM-aging [6] } \\
\text { (type (IIIIM) samples) }\end{array}$ & 414 & 449 & 51 & 38 & $0.46 / 0.60$ & $\begin{array}{l}-1.1(\mathrm{c}) \\
+4.7(\mathrm{t})\end{array}$ & $\begin{array}{l}-0.6(\mathrm{c}) \\
+2.3(\mathrm{t})\end{array}$ & $\begin{array}{l}35(\mathrm{c}) \\
31(\mathrm{t})\end{array}$ \\
\hline
\end{tabular}

Values marked (c) are related to the compression samples, and those marked (t) are related to the tension samples. Values for tan $(\delta)$ are presented for cooling/heating at frequency of $0.1 \mathrm{~Hz}$, respectively. 

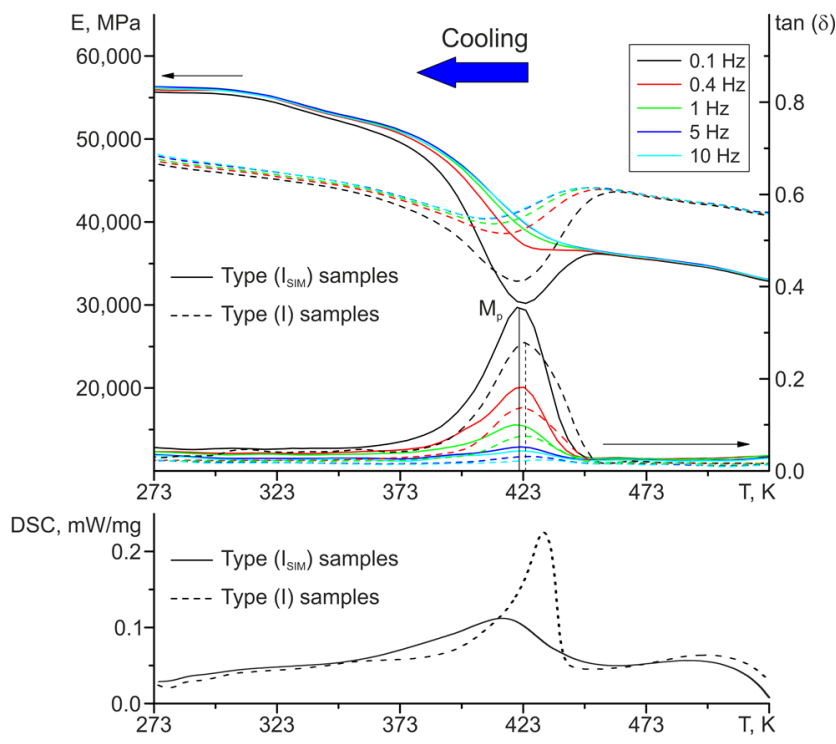

(a)

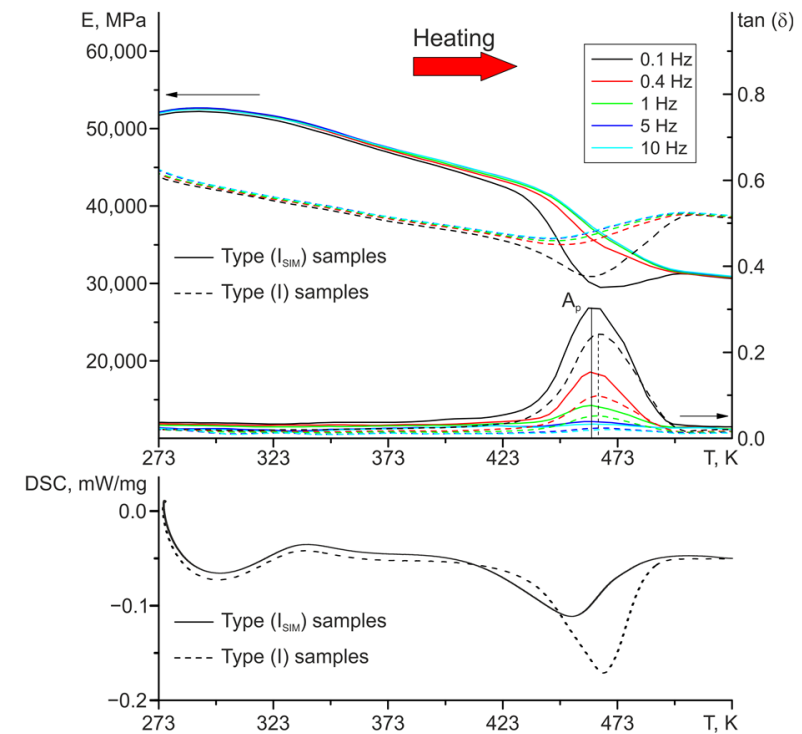

(b)

Figure 2. DMA and DSC studies of $\mathrm{Ni}_{50.3} \mathrm{Ti}_{32.2} \mathrm{Hf}_{17.5}$ polycrystals aged at $873 \mathrm{~K}$ for $3 \mathrm{~h}$ before (type (I) samples) and after SIM-aging (type ( $\left.\mathrm{I}_{\mathrm{SIM}}\right)$ samples) upon cooling (a) and heating (b).

In Figure 3 , the $\varepsilon(\mathrm{T})$ curves for NiTiHf polycrystals aged at $873 \mathrm{~K}$ for $3 \mathrm{~h}$ (type (I) samples) are shown. The value of maximum reversible strain for these crystals was found to be $-1.0 \pm 0.3 \%$ for an applied stress of $400 \mathrm{MPa}$ in compression and $+3.1 \pm 0.3 \%$ for an applied stress of $250 \mathrm{MPa}$ in tension. A further increase in stress level results in samples breaking in tension and the growth of irreversible strain in compression. The NiTiHf system possesses strong anisotropy in tension/compression in both the polycrystals and single crystals due to the anisotropy of the large maximum theoretical strain values at B2-B19' MT ( $+16.8 \%$ in tension and $-8.5 \%$ in compression) [11]. As reported by [12], the maximum theoretical strain in single crystals is characterized by crystal orientation and the stress way (tension or compression): $2.92 \%, 9.95 \%$, and $8.1 \%$ were obtained for tensile samples along the [001], [011], and [111] directions, respectively. However, the maximum strain in compression was determined to be $0.97 \%, 8.0 \%$, and $5.25 \%$ along the [001], [011], and [111] orientations, respectively. It is evident from the present work that NiTiHf polycrystals (type (I) samples) possess a low value of reversible strain in comparison with extruded polycrystals [7], theoretical calculations [13], and single crystals [14]. The first reason for such behavior in the type (I) samples is the presence of H-phase particles, which do not undergo MT. The second reason is the large grain size $(\sim 36 \mu \mathrm{m})$ compared with extruded polycrystals that are characterized by the presence of polycrystal texture and, consequently, the primary martensite variant along the extruded direction [15]. The last reason for low reversible strain is the high density of compound (001) twins [16], which are not the solution of crystallographic theory of MT and appear as geometrically necessary twins in regions with high elastic stress and facilitate compatibility between matrix deformation and the elastic strain of nano-sized particles in NiTi-based alloys. The presence of such twinning results in the impossibility of reaching the maximum reversible strain-only local areas are known in which the theoretical values could be reached. Such behavior has previously been observed in both the polycrystals and the single crystals [11]. In Figure 3, the crystals after SIM-aging are presented; they are characterized by the presence of TWSME with a maximum strain of $+1.8 \%$ and $-0.5 \%$ in tension and compression, respectively, and the impossibility of obtaining $\varepsilon(\mathrm{T})$ curves under applied stress in tension, due to the samples breaking down. The applied SIM-aging does not significantly result in the maximum reversible strain-its value decreases by $0.1 \%$, while the value of irreversible 
strain decreases by $0.2 \%$. The most evident difference after applying SIM-aging is the increase of reversible strain at minimum applied stress from $-0.4 \%$ to $-0.7 \%$ under the same stress level of $-100 \mathrm{MPa}$.

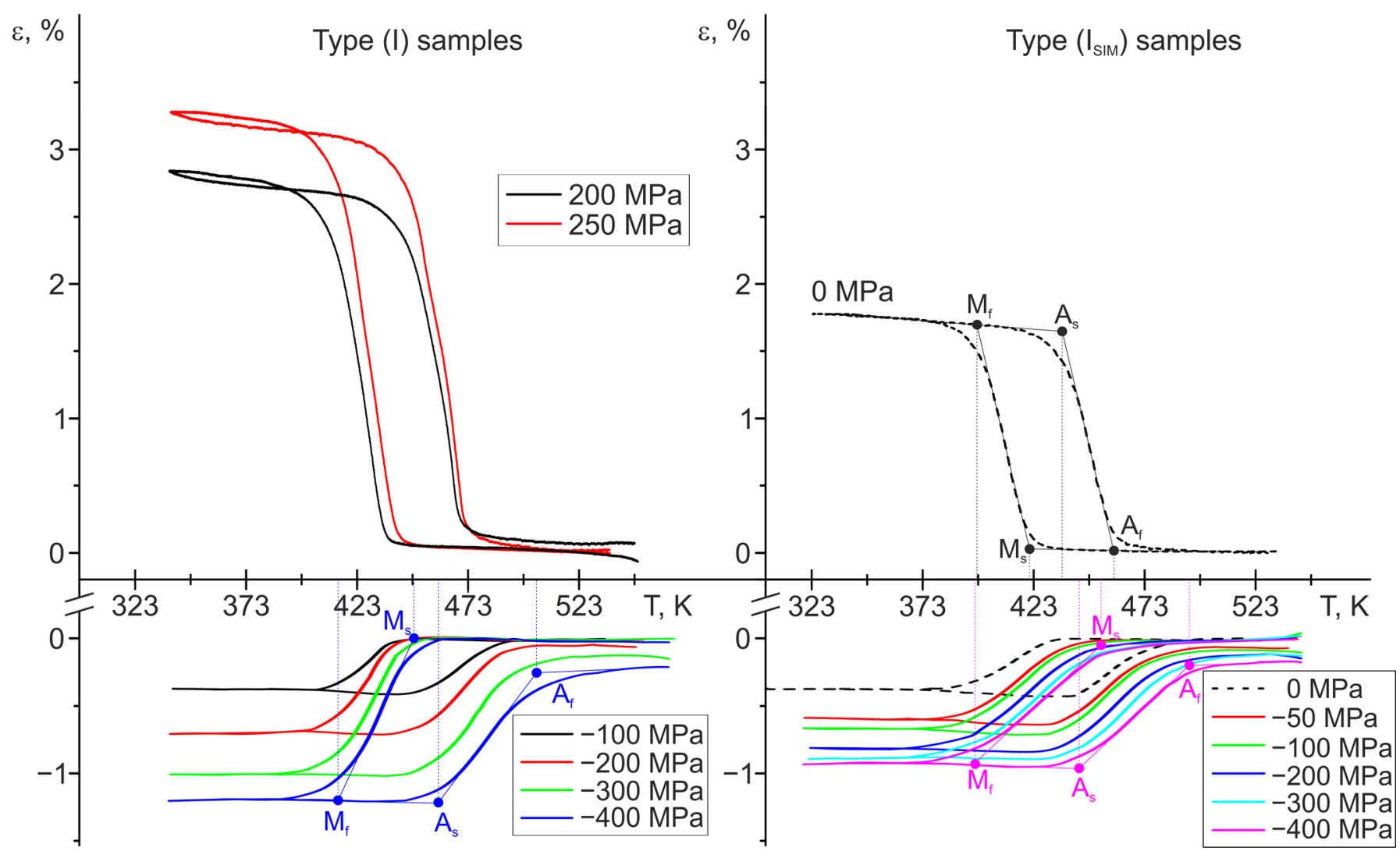

Figure 3. $\varepsilon(\mathrm{T})$ curves in tension and compression for NiTiHf aged at $873 \mathrm{~K}$ for $3 \mathrm{~h}$ : type (I) samples; type (ISIM) samples.

\section{Discussion}

To perform the full analyses of obtained results, we must compare them with the data from our previous work [6], where polycrystals with the same chemical composition$\mathrm{Ni}_{50.3} \mathrm{Ti}_{32.2} \mathrm{Hf}_{17.5}$ (at.\%) - underwent SIM-aging following the same regime. However, these polycrystals were preliminarily aged in austenite at $773 \mathrm{~K}$ for $3 \mathrm{~h}$, so they possessed a different microstructure compared to the polycrystals in the present work. The data from DMA (elastic modulus and tan ( $\delta$ )), SME, and TWSME (maximum reversible strain and temperature hysteresis) experiments are presented for each crystal type in Table 1.

The analyses of the obtained results and their comparison to the experimental data obtained for polycrystals with the same chemical composition- $\mathrm{Ni}_{50.3} \mathrm{Ti}_{32.2} \mathrm{Hf}_{17.5}$ (at.\%) aged at $773 \mathrm{~K}$ for $3 \mathrm{~h} \mathrm{[6]} \mathrm{demonstrate} \mathrm{that} \mathrm{the} \mathrm{effect} \mathrm{of} \mathrm{SIM-aging} \mathrm{on} \mathrm{viscoelastic} \mathrm{and}$ functional properties depends on the initial microstructure of heterophase alloys (Table 1). The DMA properties of both polycrystal types (type (I) and type (ISIM) samples) are presented as average values for both cooling and heating and are compared to the polycrystals aged at $773 \mathrm{~K}$ for $3 \mathrm{~h}$ with (type (IISIM) samples) and without (type (II) samples) subsequent SIM-aging (Table 1).

The increase of aging temperature from $773 \mathrm{~K}$ to $873 \mathrm{~K}$ for $3 \mathrm{~h}$ results in an increase in H-phase particle size from 10-15 $\mathrm{nm}$ [6] to $70 \mathrm{~nm}$. In addition, the particle shape changes from spherical to spindle with the increase in aging temperature. This change in microstructure leads to various changes in MTs and their parameters.

First, the increase in size along with the change in shape of the particles supposedly result in coherency loss. As reported by [17], small particles possess the lowest free energy while they are coherent, unlike large particles, which must be semi- or noncoherent in 
order to have the minimal free energy. In this case, the critical size of particles (radius for spherical precipitates) is the main parameter to define the coherency of a "particle-matrix" boundary. According to [17], this critical size can be presented as:

$$
r_{c r i t}=\frac{3 \gamma_{s t}}{4 \mu \delta^{2}}
$$

where $\gamma_{s t}$ is the extra structural contribution to the interfacial energy, $\mu$ is the shear modulus of the matrix, and $\delta$ is the lattice misfit toward particles. If we assume that $\delta$ is small, then the extra structural contribution can be defined as $\gamma_{s t} \propto \delta$.

The critical size of particles at which coherency loss occurs was estimated by using Equation (1). Using the average lattice parameters for the B2-austenite phase, B19'martensite phase [18], and H-phase particles [9,10], it was found that $r_{\text {crit }}$ is approximately $800 \mathrm{~nm}$, which is in accordance with [16]. Thus, the precipitates with sizes up to $70 \mathrm{~nm}$, which formed at $873 \mathrm{~K}$ after $3 \mathrm{~h}$, are fully coherent, as confirmed by [16], where the coherency of elongated precipitates with the austenite matrix was affirmed by high-resolution transmission electron microscopy.

It should be noted that the H-phase elongated shape results in the appearance of stress on the edges of precipitates, caused by the misfit between the matrix and particles along the particle length axis [9]. Therefore, the particles line up into elongated systems to partially relax such stress, thereby promoting the MT. It is also assumed that such stress on the edges of precipitates leads to dislocation formation and, consequently, partial coherency loss on the "precipitate-matrix" boundary upon MT.

Second, after austenite aging at $873 \mathrm{~K}$ for $3 \mathrm{~h}$, the volume fraction of precipitates increases in comparison with aging at $773 \mathrm{~K}$ for $3 \mathrm{~h}$, as evidenced by a decrease in SME strain by $0.3 \%$ in type (I) samples compared with type (II) samples. Hence, the volume fraction of a matrix, which could undergo MT, decreases, while the volume fraction of H-phase particles, which cannot undergo MT, increases. Additional proof of such behavior is an increase in TTs in the type (I) samples in comparison with the type (II) samples (Table 1), which has also been observed for NiTiHf20 polycrystals in earlier research [5].

The increase in H-phase particle volume fraction results in changes in materials' viscoelastic properties. The values of the elastic modulus in the type (I) samples for both phases are 7-8 GPa greater than those of the type II samples, and the value of the internal friction peak is $25-50 \%$ greater. This can be explained by the following: a material with dispersed particles can be defined as a composite in which the different mechanical parameters are the parameters from both the matrix and the particles. As long as the particles are deformed only elastically, do not undergo MT, and greatly increase the strength properties of material, it can be assumed that the studied polycrystals can be considered a composite, where the main contribution into the elastic modulus is made by the H-phase particles. Thus, we can use the following equation to define the elastic modulus of the material [19]:

$$
E_{\text {total }}=E_{\text {particles }} \times \delta+E_{\text {matrix }} \times(1-\delta),
$$

where $\delta$ is the volume fraction of particles. The elastic modulus of particles does not significantly differ with respect to the aging regime, $E_{\text {particles }}>E_{\text {matrix }}$, and the H-phase has close parameters; these factors result in the elastic modulus of austenite $\left(E_{A}\right)$ for type (I) samples being 8 GPa greater than that of the type (II) samples, as characterized by the smaller volume fraction of dispersed particles (Table 1).

The change in microstructure after aging at $773 \mathrm{~K}$ and $873 \mathrm{~K}$ for $3 \mathrm{~h}$, described above, results in a different effect of SIM-aging in type (I) and type (II) samples.

First, SIM-aging leads to the appearance of TWSME in both types of crystals (type ( $\left.\mathrm{I}_{\mathrm{SIM}}\right)$ and type (IISIM) samples). Type ( $\left.\mathrm{I}_{\mathrm{SIM}}\right)$ polycrystals demonstrate TWSME with a maximum strain of $-0.5 \pm 0.3 \%$ in compression and $1.8 \pm 0.3 \%$ in tension, and its value is equal to $\sim 50 \%$ of the maximum reversible strain upon cooling/heating under constant 
stress. The same behavior can be observed for crystals aged at $773 \mathrm{~K}$ for $3 \mathrm{~h}$. It should be noted that the maximum reversible strain in type (II) and type ( $\left.\mathrm{II}_{\mathrm{SIM}}\right)$ samples $(-1.3 \%$ in compression and $5.0 \%$ in tension) is greater than that in type (I) and type (ISIM) samples. Consequently, the TWSME in type (II) and type (IISIM) samples shows a greater value of reversible strain in comparison with the type (I) and type (ISIM) samples (Table 1).

It should be noted that TWSME in NiTiHf polycrystals has previously been obtained after high-cycle trainings up to 1600 cycles [20]. In this case, the physical reason for the appearance of TWSME is the internal stress field from both the dislocation clusters and the oriented $\mathrm{B} 19^{\prime}$-martensite, resulting in a maximum reversible strain of $3 \%$ in torsion and $1.5 \%$ in tension. In the present work, we demonstrate the efficiency of SIM-aging for inducing TWSME in aged NiTiHf polycrystals; the maximum value of TWSME was $1.8-2.3 \%$ in tension, regardless of the initial microstructure. The physical reason for TWSME induction after SIM-aging is the change of the short-range order of point defects and atoms (atoms of different kinds in sublattices, vacancies, interstitial atoms, substitution, and introduction impurities) in accordance with martensite symmetry [1]. Such rearrangement results in the stabilization and decrease of Gibbs free energy of oriented B19'-martensite formed under tensile/compressive stress upon SIM-aging. Thus, exactly one oriented B19'-martensite will be formed in the next stress-free thermocycle, inducing the TWSME. However, we cannot exclude the contribution of the dislocation formation and the residual B19'-martensite formation during SIM-aging (especially near the grain boundaries) to the TWSME induction.

Second, in NiTiHf polycrystals aged at $873 \mathrm{~K}$ for $3 \mathrm{~h}$, SIM-aging partially increased the elastic modulus of martensite $\left(E_{M}\right)$ (by $8 \mathrm{GPa}$ ) and the internal friction (by 25\%); however, the elastic modulus of austenite decreased by the same value of $8 \mathrm{GPa}$ (down to $31 \mathrm{GPa}$ at a temperature of $250{ }^{\circ} \mathrm{C}$ ) (Table 1 ). As for the crystals aged at $773 \mathrm{~K}$, SIM-aging increased the elastic modulus of both phases by $13 \mathrm{GPa}$ and $5 \mathrm{GPa}$ (for martensite and austenite, respectively), and the internal friction increased threefold (Table 1). According to [21], increased internal friction is evidence of increased mobility of twinning/interphase boundaries. It is assumed that such an effect is associated with increased compatibility between nano-sized H-phase particles and twinned B19'-martensite during SIM-aging. Thus, it is experimentally shown that the oriented growth of thermal-induced martensite (TWSME after SIM-aging) promotes an increase in internal friction upon MT in type ( ISIM $_{\text {) }}$ and $\left(\mathrm{II}_{\mathrm{SIM}}\right)$ samples, regardless of the H-phase particle size.

SIM-aging results in a decrease in $M_{f}$ and $A_{s}$ TTs by 15-20 K. Thus, an increase in MT temperature interval $\Delta_{1}$ (MT diffusion) is observed (Figure 3). The same MT diffusion upon stress-assisted cooling/heating cycles was observed in type $\left(\mathrm{II}_{\mathrm{SIM}}\right)$ samples, which were preliminarily aged at $773 \mathrm{~K}$ for $3 \mathrm{~h}$ [6]. This increase in MT temperature interval is the result of an increase in stored elastic energy during direct MT due to a high density of compound twins and detwinning processes. Thus, the TTs can be expressed as follows, taking into account the effect of elastic and dissipative energy and the presence of external applied stresses [4,6,22]:

$$
\begin{gathered}
M_{\mathcal{S}}(\sigma)=T_{o}(\sigma)-\frac{\left(d_{\xi=0}^{A \rightarrow M}+e_{\xi=0}^{A \rightarrow M}\right)}{-\Delta s}, \\
M_{f}(\sigma)=T_{o}(\sigma)-\frac{\left(d_{\tilde{\xi}=1}^{A \rightarrow M}(\xi)+e_{\xi=1}^{A \rightarrow M}(\xi)\right)}{-\Delta s}, \\
A_{\mathcal{S}}(\sigma)=T_{o}(\sigma)+\frac{\left(d_{\xi=1}^{M \rightarrow A}(\xi)-e_{\xi=1}^{M \rightarrow A}(\xi)\right)}{-\Delta s}, \\
A_{f}(\sigma)=T_{o}(\sigma)+\frac{\left(d_{\tilde{\xi}=0}^{M \rightarrow A}-e_{\tilde{\xi}=0}^{M \rightarrow A}\right)}{-\Delta s},
\end{gathered}
$$


where $T_{0}(\sigma)$ is the chemical equilibrium temperature; $e$ and $d$ are the elastic and dissipative energy, respectively; $\xi$ is the volume fraction of oriented martensite characterizing the overall process of MT; and $\Delta_{S}$ is the change of entropy during MT. From this, the MT diffusion (the difference between starting and finishing temperature of direct or reverse MT) can be expressed as follows:

$$
\Delta_{1}\left(M_{s}-M_{f}\right)=\frac{e_{\xi=1}(\xi)+d_{\xi=1}(\xi)-e_{\xi=0}-d_{\xi=0}}{-\Delta s}
$$

Equations (3)-(7) show that an increase in stored elastic energy upon MT (at the maximum volume fraction of oriented martensite) results in a decrease in $M_{f}(\sigma)$ and $A_{s}(\sigma)$ TTs and a corresponding increase in MT diffusion $\left(\Delta_{1}\right)$.

It should be noted that the relation of TTs defines the MT type. For example, in type (I) samples, the TTs at low applied stress (<400 MPa) are related as $M_{S}<A_{s}$ (Figure 3). A further increase in stress leads to a change of MT type, and TTs are related as $A_{s}<M_{s}$. So long as SIM-aging provides the TTs shift, their relation to stress-assisted MTs is the same: $A_{S}<M_{S}$. This relation of TTs is defined by the contribution of elastic and dissipative energies. According to Equations (3) and (5), the difference between $A_{s}$ and $M_{s}$ temperatures can be written as follows:

$$
A_{S}(\sigma)-M_{S}(\sigma)=\frac{\left(d_{\xi=1}^{M \rightarrow A}(\xi)-e_{\tilde{\xi}=1}^{M \rightarrow A}(\xi)\right)+\left(d_{\tilde{\xi}=0}^{A \rightarrow M}+e_{\xi=0}^{A \rightarrow M}\right)}{-\Delta s}
$$

Taking into account the fact that the value of dissipative energy during MT is almost constant and the value of elastic energy significantly increases with the volume fraction of oriented martensite ( $\xi$ ), two assumptions can be made to simplify Equation (7): $d_{\xi=1}^{M \rightarrow A}(\xi)=d_{\xi=0}^{A \rightarrow M} \xi=d, e_{\xi=1}^{M \rightarrow A}(\xi) \gg e_{\xi=0}^{A \rightarrow M}$. Thus, Equation (8) can be rewritten as:

$$
A_{s}(\sigma)-M_{s}(\sigma)=\frac{1}{-\Delta s}\left(2 d-e_{\xi=1}^{M \rightarrow A}(\xi)\right)
$$

It is obvious that if the stored energy during forward $\mathrm{MT}\left(e_{\xi=1}^{M \rightarrow A}(\xi)\right)$ becomes much greater than the dissipative energy, then the reverse MT can occur at temperatures lower than $M_{S}$ under the condition of counteracting chemical driving force:

$$
A_{S}(\sigma)-M_{S}(\sigma)=\frac{1}{-\Delta s}\left(2 d-e_{\xi=1}^{M \rightarrow A}(\xi)\right)<0 .
$$

Consequently, in order for $A_{S}<M_{S}$ to be true, the following condition must be fulfilled: $d<2 e_{\xi=1}^{M \rightarrow A}(\xi)$. Thus, during SIM-aging, one stress-induced martensite variant is formed, which is maintained for the entire duration of SIM-aging. This leads to a decrease in Gibbs free energy of such a martensite variant, causing it to form at lower stresses and/or higher temperatures. The additional internal stress fields near spindle-shaped H-phase dispersed particles combined with the oriented martensite variant growth result in TWSME induction. It should also be noted that MT occurs with the low elastic modulus softening in type (ISIM) samples, which can be explained by significant elastic distortions formed upon SIM-aging. It is assumed that such distortions are formed because of the presence of nonuniaxial precipitates and promote MT by decreasing the required softening of the austenite lattice to start the forward MT.

\section{Conclusions}

It has been shown that SIM-aging at $428 \mathrm{~K}$ for $12 \mathrm{~h}$ under tensile and compressive stresses of $300 \mathrm{MPa}$ and $400 \mathrm{MPa}$, respectively, of $\mathrm{Ni}_{50.3} \mathrm{Ti}_{32.2} \mathrm{Hf}_{17.5}$ polycrystals preliminarily aged at $873 \mathrm{~K}$ for $3 \mathrm{~h}$, with an average grain size of $\sim 36 \mu \mathrm{m}$, significantly changes the functional and viscoelastic properties of material. Because of the dispersed particles of the H-phase, with spindle shapes of sizes up to $70 \mathrm{~nm}$, the type (I) samples possess good 
strength properties and high transformation temperatures $\left(M_{p}=423 \mathrm{~K}, A_{p}=463 \mathrm{~K}\right)$. The subsequent SIM-aging resulted in the appearance of TWSME with a strain of $-0.5 \%$ in compression and $1.8 \%$ in tension, a change in elastic modulus ( $E_{M}$ increased by $8 \mathrm{GPa}$ and $E_{A}$ decreased by $8 \mathrm{GPa}$ ), and an increase in internal friction (by $25 \%$ ).

In contrast, the precipitation of smaller spherical particles in crystals of the same chemical composition aged at $773 \mathrm{~K}$ for $3 \mathrm{~h}$ resulted in the appearance of TWSME with a strain of $-0.6 \%$ in compression and $2.3 \%$ in tension, a significant increase in the elastic moduli of both phases (by $13 \mathrm{GPa}$ and $5 \mathrm{GPa}$ for $\mathrm{E}_{\mathrm{M}}$ and $\mathrm{E}_{\mathrm{A}}$, respectively), and a significant increase in internal friction (threefold).

Thus, first, SIM-aging under tensile and compressive stresses of $\mathrm{Ni}_{50.3} \mathrm{Ti}_{32.2} \mathrm{Hf}_{17.5}$ polycrystals containing H-phase particles of different sizes (10-15 nm and up to $70 \mathrm{~nm}$ in polycrystals aged at $773 \mathrm{~K}$ and $873 \mathrm{~K}$ for $3 \mathrm{~h}$, respectively) is an efficient way to induce TWSME. Second, SIM-aging results in an increase of the internal friction peak at oriented growth of thermal-induced martensite, widening of MT temperature intervals, and the observation of reverse MT at $A_{S}<M_{S}$ under the condition of counteracting chemical driving force due to stored elastic energy upon forward MT. In the studied polycrystals, the value of TWSME, the elastic modulus of austenite, and the value of the internal friction peak after SIM-aging are determined by the size, shape, and volume fraction of $\mathrm{H}$-phase particles.

To summarize, the internal microstructure of a material strongly affects the viscoelastic properties and regularities of martensitic transformations in a NiTiHf system. Due to SIM-aging, it is not only possible to change material properties but to also control them. However, further studies are necessary to determine the full influence of SIM-aging on a material-its properties, microstructure, and the coherency of dispersed particles of different shapes.

Author Contributions: Conceptualization, E.Y.P. and Y.I.C.; methodology, Y.I.C.; validation, A.I.T. and E.E.T.; formal analysis, E.Y.P. and E.E.T.; investigation, A.I.T.; resources, Y.I.C. and I.K.; writingoriginal draft preparation, A.I.T.; writing-review and editing, E.Y.P., E.E.T. and Y.I.C.; visualization, A.I.T.; supervision, E.Y.P. and Y.I.C.; project administration, A.I.T.; funding acquisition, E.S.M. All authors have read and agreed to the published version of the manuscript.

Funding: This research was funded by the Ministry of Education and Science of the Russian Federation, Project No. 0721-2020-0022.

Data Availability Statement: The data used in this article are presented in the manuscript.

Conflicts of Interest: The authors declare no conflict of interest.

\section{References}

1. Otsuka, K.; Ren, X. Mechanism of martensite aging effects and new aspects. Mater. Sci. Eng. A 2001, 312, 207-218. [CrossRef]

2. Timofeeva, E.E.; Panchenko, E.Y.; Pichkaleva, M.V.; Tagiltsev, A.I.; Chumlyakov, Y.I. The effect of stress-induced martensite ageing on the two-way shape memory effect in $\mathrm{Ni}_{53} \mathrm{Mn}_{25} \mathrm{Ga}_{22}$ single crystals. Mater. Lett. 2018, 228, 490-492. [CrossRef]

3. Tsuchiya, K.; Tateyama, K.; Sugino, K.; Marukawa, K. Effect of aging on the rubber-like behavior in Cu-Zn-Al martensites. Scr. Met. Mater. 1995, 32, 259-264. [CrossRef]

4. Kustov, S.; Pons, J.; Cesari, E.; Van Humbeeck, J. Chemical and mechanical stabilization of martensite. Acta Mater. 2004, 52, 4547-4559. [CrossRef]

5. Coughlin, D.R.; Casalena, L.; Yang, F.; Noebe, R.D.; Mills, M.J. Microstructure-property relationships in a high-strength 51Ni29Ti-20Hf shape memory alloy. J. Mater. Sci. 2016, 51, 766-778. [CrossRef]

6. Tagiltsev, A.I.; Panchenko, E.Y.; Timofeeva, E.E.; Chumlyakov, Y.I.; Fatkullin, I.D.; Marchenko, E.S.; Karaman, I. The effect of stress-induced martensite aging in tension and compression on B2-B19' martensitic transformation in Ni50.3Ti32.2Hf17.5 high-temperature shape memory alloy. Smart Mater. Struct. 2021, 30, 025039. [CrossRef]

7. Saghaian, S.M.; Karaca, H.E.; Tobe, H.; Turabi, A.S.; Saedi, S.; Saghaian, S.E.; Chumlyakov, Y.I.; Noebe, R.D. High strength NiTiHf shape memory alloys with tailorable properties. Acta Mater. 2017, 134, 211-220. [CrossRef]

8. Karaca, H.E.; Saghaian, S.M.; Ded, G.; Tobe, H.; Basaran, B.; Maier, H.J.; Noebe, R.D.; Chumlyakov, Y.I. Effects of nanoprecipitation on the shape memory and material properties of an Ni-rich NiTiHf high temperature shape memory alloy. Acta Mater. 2013, 61, 7422-7431. [CrossRef]

9. Han, X.D.; Wang, R.; Zhang, Z.; Yang, D.Z. A new precipitate phase in a TiNiHf high temperature shape memory alloy. Acta Mater. 1998, 46, 273-281. [CrossRef] 
10. Yang, F.; Coughlin, D.R.; Phillips, P.J.; Yang, L.; Devaraj, A.; Kovarik, L.; Noebe, R.D.; Mills, M.J. Structure analysis of a precipitate phase in an Ni-rich high-temperature NiTiHf shape memory alloy. Acta Mater. 2013, 61, 3335-3346. [CrossRef]

11. Sehitoglu, H.; Wu, Y.; Patriarca, L.; Li, G.; Ojha, A.; Zhang, S.; Chumlyakov, Y.; Nishida, M. Superelasticity and Shape Memory Behavior of NiTiHf Alloys. Shape Mem. Superelasticity 2017, 3, 168-187. [CrossRef]

12. Saghaian, S.M.; Karaca, H.E.; Souri, M.; Turabi, A.S.; Noebe, R.D. Tensile shape memory behavior of Ni50.3Ti29.7Hf20 high temperature shape memory alloys. Mater. Des. 2016, 101, 340-345. [CrossRef]

13. Saghaian, S.M.; Karaca, H.E.; Tobe, H.; Souri, M.; Noebe, R.; Chumlyakov, Y.I. Effects of aging on the shape memory behavior of Ni-rich Ni50.3Ti29.7Hf20 single crystals. Acta Mater. 2015, 87, 128-141. [CrossRef]

14. Wu, Y.; Patriarca, L.; Sehitoglu, H.; Chumlyakov, Y. Ultrahigh tensile transformation strains in new Ni50.5Ti36.2Hf13.3 shape memory alloy. Scr. Mater. 2016, 118, 51-54. [CrossRef]

15. Chen, X.; Chen, W.; Ma, Y.; Zhao, Y.; Deng, C.; Peng, X.; Fu, T. Tension-Compression asymmetry of single-crystalline and nanocrystalline NiTi shape memory alloy: An atomic scale study. Mech. Mater. 2020, 145, 103402. [CrossRef]

16. Santamarta, R.; Arróyave, R.; Pons, J.; Evirgen, A.; Karaman, I.; Karaca, H.E.; Noebe, R.D. TEM study of structural and microstructural characteristics of a precipitate phase in Ni-rich Ni-Ti-Hf and Ni-Ti-Zr shape memory alloys. Acta Mater. 2013, 61, 6191-6206. [CrossRef]

17. Porter, D.A.; Easterling, K.E.; Sherif, M.Y. Phase Transformations in Metals and Alloys, 3rd ed.; CRC Press: Boca Raton, FL, USA, 2014; pp. 146-167.

18. Stebner, A.P.; Bigelow, G.S.; Yang, J.; Shukla, D.P.; Saghaian, S.M.; Rogers, R.; Garg, A.; Karaca, H.E.; Chumlyakov, Y.; Bhattacharya, K.; et al. Transformation strains and temperatures of a nickel-titanium-hafnium high temperature shape memory alloy. Acta Mater. 2014, 76, 40-53. [CrossRef]

19. Vinson, J.R.; Sierakowski, R.L. The Behavior of Structures Composed of Composite Materials, 2nd ed.; Kluwer Academic Publishers: Dordrecht, The Netherlands, 2011; pp. 375-390.

20. Hayrettin, C.; Karakoc, O.; Karaman, I.; Mabe, J.H.; Santamarta, R.; Pons, J. Two way shape memory effect in NiTiHf high temperature shape memory alloy tubes. Acta Mater. 2019, 163, 1-13. [CrossRef]

21. Shuitcev, A.; Li, L.; Markova, G.V.; Golovin, I.S.; Tong, Y.X. Internal friction in Ti29.7Ni50.3Hf20 alloy with high temperature shape memory effect. Mater. Lett. 2020, 262, 127025. [CrossRef]

22. Beke, D.L.; Daróczi, L.; Samy, N.M.; Tóth, L.Z.; Bolgár, M.K. On the thermodynamic analysis of martensite stabilization treatments. Acta Mater. 2020, 200, 490-501. [CrossRef] 